\title{
Complementing the treatment of a major depressive disorder patient with Ruqyah Shar'iyyah therapy: A Malaysian case study
}

\section{Zul Azlin Razali}

Department of Psychiatry, Faculty of Medicine and Health Science, Universiti Sains Islam Malaysia (USIM), Kuala Lumpur, Malaysia

\section{Nor Azian Ab Rahman}

Institute of Malay World and Civilization, National University of Malaysia (UKM), Selangor, Malaysia.

\section{Supyan Husin}

Institute of Malay World and Civilization, National University of Malaysia (UKM), Selangor, Malaysia.

Corresponding Author:

Zul Azlin Razali, Faculty of Medicine and Health Science, Universiti Sains Islam Malaysia (USIM), Pandan Indah Campus, Kuala Lumpur, Malaysia.

Email: zulazlin@usim.edu.my

\section{Abstract}

This paper describes a female patient with major depressive disorder with psychotic features, who underwent mainstream psychiatric treatment complemented with ruqyah shar'iyyah (incantations based on Qur'an and prophetic traditions) healing in Malaysia. The patient faced the stigmatization of mental health within her family and had poor coping mechanisms, in addition to an incomplete understanding of what characterizes a religiously observant Muslim faith healer, in 
the early phases of her illness. The patient had periods of non-compliance with psychiatric care in between various ruqyah shar'iyyah, treatment periods, and faced a relapse that led to hospital admission. The patient's outcome improved after she complemented her psychiatric treatment with ruqyah shar'iyyah, that complied with Islamic creed and law. The importance of the inter-related systems of medical and psycho-spiritual treatments needs to be emphasized as it is crucial to the psychological wellbeing of the patient. The case report illustrates that ruqyah shar'iyyah, a practice encouraged by the Prophet Muhammad is believed to be a therapeutic remedy for any disorder, and can be used as complementary spiritual-based treatment to mainstream psychiatry, bringing multiple benefits across various cultural groups of Muslims.

Keywords: complementary medicine, Qur'anic healing, psycho-spiritual, demonic possession, ruqyah

\section{Case Presentation}

A 40-year-old Malay Muslim woman reported suffering from insomnia, poor concentration, and feelings of sadness and worthlessness in 2006. Within two weeks of the onset of the symptoms, she developed multiple series of panic attacks that were described as feelings of physical numbness, heat sensations, palpitations, fear of going crazy, and fear of losing control. Being a fulltime domestic caretaker, the patient's family was inevitably effected as she was unable to complete her responsibilities. She also began having recurrent thoughts of death without demonstrating overt suicidal ideation.

The patient consulted a traditional healer as her primary choice of treatment. She and her family believed that some form of spiritual disturbances were at the heart of her problem. She had consulted more than ten healers who applied an assortment of treatment methods. Some of the treatments involved beatings and infliction of physical pain. Retrospectively, the patient recalled that some of the healers were not using authentic recitations from the Quran or prophetic traditions despite portraying themselves as ustadz (one who is viewed as knowledgeable in the teachings of Islam). Almost all the healers mentioned a third party who had supposedly performed black magic or sihr on the patient, without being able to pinpoint the actual perpetrator. The patient spent a significant amount of money on these healers but to no avail, as none of them could alleviate her psychological misery. She continued to suffer for one month, and subsequently developed psychosis.

One of the first signs of her psychotic behavior was when she was seen talking to herself. On another occasion, she threatened her husband with a kitchen knife, unprovoked. Her disruptive behaviors forced the family to seek help from the local authorities to admit her to the psychiatric unit of a nearby 
hospital. This admission to the ward occurred one year after the onset of depressive symptoms. Relevant laboratory investigations were done, including electrocardiogram and thyroid function tests. No abnormalities were detected. There were no symptoms suggestive of hypomania or mania. The patient also demonstrated some premorbid personality traits. Her dependence on her husband became more apparent as the illness worsened. One of the conjectures about the patient's stressor was the suspicion that her youngest child had a learning disability; however, she was reluctant to take him for professional assessment and intervention.

The patient was diagnosed with major depressive disorder with psychotic features. Her husband did not think treatment was improving her condition. There were times in the ward that her behavior was so disruptive that she needed to be physically restrained. The patient and her family were traumatized by this experience of restraint. Once she was considered more stable, her family requested temporary home-leave to seek treatment from a renowned local Islamic faith healer, "UB". At this stage, she was prescribed daily medication (10 $\mathrm{mg}$ oral escitalopram and $50 \mathrm{mg}$ quetiapine extended release), and several low doses of short-acting benzodiazepine pro re nata.

UB was the founder of an established spiritual healing center in one of the main cities in Malaysia that utilizes ruqyah shar'iyyah as the primary form of treatment. Ruqyah shar'iyyah is a remedy by recitation of invocations based on Quran and authentic prophetic traditions. The patient was taught the incantations and was encouraged to practice the ruqyah on herself. During the treatment, UB put great emphasis on basic Islamic tenets such as the attributes of God, the concept of illness in Islam, and how sickness can be a test of faith and a means for expiation of sins or forgiveness from Allah. No herbs or any form of medicinal consumption was prescribed by UB. The patient continued taking the medications prescribed by her psychiatrist as encouraged by UB. She returned to the ward from her three days home-leave and was then discharged a couple of days later in view of her improvement. The psychotic symptoms had subsided.

Following several more encounters with UB after discharge, her family was impressed at the remarkable improvement. The patient did not even need benzodiazepine to help her sleep. She was compliant with the antidepressant prescribed. She was in partial remission at this point and maintained regular follow-ups with both modes of treatment, psychiatric clinic (conventional medicine) and the ruqyah shar'iyyah (with UB). After one year, the patient defaulted on the psychiatric follow-ups. Her husband, parents, and siblings had a negative perception toward the fact that the patient was under the care of the mental health service. They equated the need for psychiatric intervention as being mentally crazy. In their view, ascribing the emotional and mental turmoil faced by the patient to the doings of demons seems somehow more acceptable 
and less shameful than admitting she was being treated by modern psychiatric therapy. For about three years, the patient was able to perform her basic function as homemaker without any psychiatric treatment.

The patient came back to the psychiatric inpatient setting in 2011. The relapse episode was presented as insomnia, depressed mood, anhedonia, low energy, poor concentration, and psychomotor retardation. The relapse was complicated by anxiety symptoms where she harbored constant deep worries about almost every task and issue. She also exhibited nihilistic delusions where she had the conviction life was meaningless and she felt as if she had no soul. The patient was diagnosed with relapsed major depressive disorder with psychosis and generalized anxiety disorder. Medications were restarted with some adjustment from the previous types and dosage.

She spent two weeks in the psychiatric ward after which she was discharged with medication. She and her family were given regular psycho-education regarding the proper understanding of psychiatric illness. The patient continued to receive regular religious counseling and ruqyah shar'iyyah treatment from UB during this relapse. The patient was compliant with the medication and follow-ups for the next four years.

In August 2015, the patient was deemed to be in remission while on oral escitalopram $10 \mathrm{mg}$ OD and oral quetiapine (extended release) $50 \mathrm{mg}$ ON. UB also strongly encouraged the patient to continue the conventional medicine in the hospital. She maintained a close relationship with UB's spiritual healing center.

\section{Diagnostic Formulation}

The patient meets the criteria for the DSM-V diagnosis: 296.34, F33.3 Major Depressive Disorder, Recurrent Episode, With Psychotic Features

\section{Cultural Formulation}

\section{Cultural Identity}

Patient is a middle-aged housewife in a working-class Muslim Malay family. She has up to secondary school level of formal education. She considers herself to be a practicing Muslim, however acknowledges that her understanding of Islamic creed and tenets was lacking especially prior to the onset of the illness. Malaysia is a multicultural nation, and the urban setting where the patient lives is a typical example of the moderate mix of races and religions. Malay society is deeply rooted in the belief of native traditional healings (Razali, 2000; Phang, 
Marhani, \& Salina, 2010); these originated from the practice of ancestors who had a mix of paganism and animism beliefs prior to the arrival of Islam. As such, the healing methods employed often have a direct or indirect relation to the rituals or beliefs of the past that still influence the mindset of today's generation.

However, over time and with the spread of Islamic creed and tenets, Islamic faith healers, known locally as ustadz (Arabic for teachers), have gradually become more popular as the primary alternative healers in the Malay Muslim society (Kasimin, 2009), as opposed to the traditional healers. Attributing symptoms of mental illness such as hallucination, depressed mood, and panic attacks, to demonic disturbance (jinn) is a common occurrence in the Malay Muslim society in Malaysia (Razali, 2000). It is not uncommon to see the traditional Malay healers or shamans, known locally as bomoh, portray themselves as ustadz, in other words, rebranding their healing services and methods to appear to be an Islamic form of treatment in order to gain credibility and social acceptance, despite going against the actual creed of Islam. Some of the bomoh practices and healing methods are still mixed with animism originating from paganism predating Islamic proselytism in the Malay Archipelago (Kasimin, 2009). This phenomenon ultimately causes confusion with patients such as this woman, who may not be able to discern any credibility between the two types of healers. The confusion is compounded due to the differences in definition, or even lack of understanding of the definition, as to what kind of healing is acceptable within the Islamic context.

\section{Cultural Explanation of Individual Illness}

In the early stages of the illness, the patient shared the family's belief that her illness was primarily a result of demonic disturbance via black magic or sihr. Sihr is defined as whatever is caused by hidden or subtle forces. In Islamic tradition, sihr is a contract, spoken or written, that will affect the body, heart, or mind of the one bewitched without actually coming in contact with him (Philips, 2007). The majority of Muslim scholars hold that magic is real and severe warnings and punishment await its practitioner.

In this case, this form of disease attribution was reinforced further with the meetings of several healers who applied various methods which were viewed as not Islamic. At one point, the family was focused on proactively searching to identify the perpetrator of the supposed sihr. After going through a few sessions with $\mathrm{UB}$, the patient put less emphasis on the attribution to sihr as the cause of her mental illness. She placed more priority on getting closer to Allah and to be consistent with her worship rituals. She practiced incantations or prayers from the Quran and the authentic narrations of hadith while continuing taking her medications. 


\section{Cultural Elements of Psychosocial Treatment Delivery}

Instead of dismissing the patient's notion of attributing the illness to demonic possession, she was encouraged by the hospital to seek alternative routes of spiritual treatment provided she continued her psychiatric care. Some of her treating doctors cautioned her to only seek faith healing that is grounded in Islamic teachings or creed, as opposed to the traditional Malay healing with roots in paganism and animism. The doctors included in her psycho-education the understanding that psychiatric illness is not to be blamed on the patient's past actions or on moral and spiritual matters only. They also stressed that $\mathrm{Al}$ lah, the All-Encompassing, All-Loving and All-Knowing, is testing the patient with psychiatric illness in order to bring out the best in her (Hamdan, 2008).

Ruqyah shar'iyyah is a form of treatment which includes incantations from the Quran and authentic hadith narrations. It is a theologically acceptable form of treatment as opposed to the traditional Malay healing that is rooted in paganistic practices laden with polytheistic (shirk) and superstitious (khurafat) elements (Kasimin, 2009). There are scholarly writings that equate ruqyah shar'iyyah exclusively to spiritual Islamic exorcism although it can be applied for physical illness as well (Philips, 2007). Prior to her first admission to the ward, the patient had been subjected to several healing practitioners that were practicing superstitious as well as aggressive methods that incurred physical pain to her. Later, as illustrated earlier, UB taught her self-ruqyah with authentic Islamic prayers. Apart from this, the sense of self-empowerment, meaningmaking, declared receptivity toward God, and instilling of the certainty in the power and love of God during the ruqyah shar'iyyah therapy provided her strength in the road toward recovery (Eneborg, 2013).

Later in the recovery phase, despite still believing that there was some involvement from demons in causing her illness, the patient also started to put importance on the need to consult a psychiatrist and to take her medications regularly. When Islam or any spiritual message is used effectively by a practitio-

ner (whether a doctor or faith healer), it can provide sufficient de-stigmatizing language and understanding that can better fit the patient's religious or cultural context to remove the barriers of service delivery. Some patients can be more compliant to mainstream modern treatment when teachings of Islam are inculcated (Hamdan, 2008).

\section{Cultural Elements of the Clinician-Patient Relationship}

Patient's acceptance of the professional psychiatric help for her condition was only apparent after she visited UB, an established Islamic faith healer with good reputation in the local community. It has been shown that familiarity with religious figures and the perceived benefits of self-disclosure affects the preference 
of consulting a religious advisor over a psychological professional for intervention of psychological distress (Crosby \& Bossley, 2012). Religious advisors can be very important allies in mental health services as they have the potential to expedite referral to psychiatric services and improve patients' compliance to treatment (Phang, Marhani, \& Salina, 2010).

The cultural awareness and the prudent navigation in balancing the patient's conviction and wishes, and the need for proper psychiatric intervention proved to be the vital component in getting the patient into remission. On the part of the treating doctors, a culturally sensitive approach in consultation especially with regard to jinn possession and spiritual therapy is paramount (Pouchly, 2012).

\section{Discussion}

On the last admission (the relapse), the patient's complete diagnosis was Major Depressive Disorder with psychotic features co-morbid Generalized Anxiety Disorder. Ruqyah shariyyah has become a more popular mode of spiritual healing among Muslim for depressive illness (Afifuddin \& Nooraini, 2016). In a recent systematic review, the interventions by traditional healers in depression and anxiety showed some effectiveness (Nortje, Oladeji, Gureje, \& Seeda, 2016).

The relapse followed the patient's discontinuation of medication and follow-up treatment. The stigmatization of mental disorders is a widespread phenomenon in developing Asian countries. One of the common stigmatizations is that a mentally ill patient is dangerous and aggressive. A contributing factor to the preference of religious and traditional healers for psychological distress is the stigma surrounding mental health (Crosby \& Bossley, 2012). Although patients consult religious advisors for validation and acknowledgement of their spiritual issues, the religious advisors can in turn play a key role in strengthening the compliance of the patient to psychiatric treatment as demonstrated in this case. (Phang, Marhani, \& Salina, 2010; Eneborg, 2016).

Collaboration of the clinicians and the religious advisors is the way forward to improve health care (Pouchly, 2012). More objective and empirical studies should be embarked on to investigate the utility and the effectiveness of ruqyah shar'iyyah as a complementary treatment for mental disorders. The patient's remission could not be shown in this case as the direct effect of this spiritual healing. Ruqyah shar'iyyah exert its effects in three possible ways in this case: 1) a direct therapeutic result of which the mechanism is still unknown, 2) an indirect placebo effect, or 3) by increasing the likelihood of getting treatment and maintaining compliance.

More importantly, the understanding of the nature of jinn and unseen dis- 
turbances based on authentic Islamic evidence is of the greatest importance. Local traditions and cultural values pose significant influence in shaping the population's understanding of demonic possession which may run counter to the authentic Islamic point of view (Philips, 2007). Question that should be asked and discussed adequately is, do we need to differentiate whether it is demonic possession or purely psychiatric illness? This, in turn, would address the hesitation that we should do both, modern psychiatric treatment and ruqyah shar'iyyah, regardless whether there is an involvement of spiritual beings. In the authentic Prophetic tradition, it was not clear that demonic possession was diagnosed explicitly in a regular manner. With the advent of modern medicine, mental illnesses have been increasingly found to have biological and psychological underpinnings.

This case study illustrates the complementary nature of ruqyah shar'iyyah in the treatment of major depressive disorder. As demonstrated above, it has highlighted the importance of bringing to the fore the proper understanding of jinn possession and ruqyah shar'iyyah. Besides collaboration of clinicians and religious advisors, Muslim doctors and patients would benefit tremendously if the utilization of ruqyah shar'iyyah is studied rigorously. In line with the Prophetic tradition, ruqyah shar'iyyah is a form of supplication and should not be made as an exclusive practice of the elite few. Thus, it would not merely serve as complementary but as a crucial part in an integrated treatment system.

\section{References}

Afifuddin, M. M., \& Nooraini, O. (2016). The Ruqyah Syar'iyyah Spiritual Method as an Alternative for Depression Treatment. Mediterranean Journal of Social Sciences, 7(4), 406. https://doi.org/10.5901/mjss.2016.v7n4p406

Crosby, J. W., \& Bossley, N. (2012). The religiosity gap: Preferences for seeking help from religious advisors. Mental Health, Religion \& Culture, 15(2), 141-159. https:// doi.org/10.1080/13674676.2011.561485

Eneborg, Y. M. (2013). Ruqya Shariya: Observing the rise of a new faith healing tradition amongst Muslims in east London. Mental Health, Religion \& Culture, 16, 1080-1096. https://doi.org/10.1080/13674676.2012.740631

Hamdan, A. (2008). Cognitive restructuring: An Islamic perspective. Journal of Muslim Mental Health, 3(1), 99-116. https://doi.org/10.1080/15564900802035268

Kasimin, A. (2009). Sihir: Suatu amalan kebatinan. (Sihr: A form of spiritual practice). Penerbit, Malaysia, Universiti Kebangsaan Malaysia.

Nortje, G., Oladeji, B., Gureje, O., \& Seedat, S. (2016). Effectiveness of traditional healers in treating mental disorders: A systematic review. Lancet Psychiatry, 3(2), 154170. https://doi.org/10.1016/S2215-0366(15)00515-5

Phang, C. K., Marhani, M., \& Salina, A. A. (2010). Prevalence and experience of contact with traditional healers among patients with first-episode psychosis in Hospital Kuala Lumpur. Malaysian Journal of Psychiatry, 19(2), 7-8. 
Philips, A. A. B. (2007). The exorcist tradition in Islam. R. Ansary (Ed.). Sharjah, U.A.E. : Dar Al Fatah, 1997.

Pouchly, C. A. (2012). A narrative review: Arguments for a collaborative approach in mental health between traditional healers and clinicians regarding spiritual beliefs. Mental Health, Religion \& Culture, 15(1), 65-85. https://doi.org/10.1080/136 74676.2011 .553716

Razali, S. M., \& Najib, M. A. M. (2000). Help-seeking pathways among Malay psychiatric patients. International Journal of Social Psychiatry, 46(4), 281-289. https://doi. org/10.1177/002076400004600405 